\section{Chipper Headrigs for Processing Small Logs}

\author{
by P. M. Morley
}

Manager, Special Projects, Woodlands, Consolidated-Bathurst Limited, Montreal, P.Q.

Oxf. 832.1

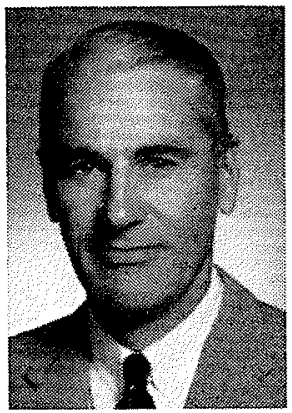

One of the most interesting developments over the last few years in the primary processing of small-diameter roundwood are the chipper headrig mills, often called chipper-canters. In fact, the chipper headrig (and edger) may likely be recognized as the most important innovation in mechanical conversion since the invention of the mechanical ring debarker. Common to all these mills is the production of chips rather than slabs by the action of a varying number and arrangement of knives which replace the conventional band or circular saw to give either a profiled log or cant. Further processing into lumber is achieved by a sawing unit incorporated as part of the machine or by in-line or independently operated units.

The advantages of chipper headrig mills over conventional sawing and separate chipping are high lineal-foot productivity, lower manpower requirements, low sawdust yield (estimated as a reduction of from an average $15 \%$ of cubic volume, depending on whether band or circular sawn, down to $5 \%$ ) and the production of pulpwood chips. No one unit gives satisfactory performance on all these counts. For example, the lower manpower required and high lumber recovery obtained by having a profiling headrig and saw unit incorporated in the same machine may be offset by a certain inflexibility in sawing, and chips that do not meet some pulp mill standards. Similarly, units making cants may give poorer lumber recovery and require more manpower but have greater flexibility and produce a more uniform pulpwood chip. All units have the disadvantage that unless there is also a conventional chipper present there will be a certain residue loss from inability to process edgings and trim waste. If, added to this, it is evident that certain very small diameter, crooked or defective logs might be better chipped completely rather than processed, there may be economic justification for a separate chipper in highvolume mills.

Chipper headrigs would appear to have their best application as an auxiliary to the main sawmill whereby small diameter logs ( $9^{\prime \prime}$ and less) would be diverted, then partly or totally processed at a high feed speed thus permitting more economical sawing of the larger logs. Partial processing would mean that the cant would be directed back into the main mill after the chipper headrig. Another application would be as a processing unit for the straighter and sounder bolts produced in a regular eight-foot pulpwood operation. After debarking, the better bolts could be converted into cants and chips while the balance could be processed directly into chips using a conventional chipper or sent unprocessed to the pulp mill as roundwood.

A brief description of the units now in commercial production is given here. For more details, there are several excellent studies on unit performance which are listed at the end of this summary.

(a) BEAVER manufactured by Stetson-Ross, Seattle, Washington. The Beaver has a patented feeding mechanism consisting of paralleling v-type chains which automatically compensate for a reasonable amount of sweep or taper in the log. Chips are removed by a pair of segmented cutterheads with knives operating horizontally, top and bottom, giving a 'planing' effect, followed immediately by two lateral segmented cutterheads, which perform at a feed speed of 185 feet a minute. In the Beaver operations seen (Del Connor Lumber Company, Darby, Montana) which was the first commercial installation, the cant was further processed by an inline double-arbor dimension machine to produce $1 \mathrm{x}$ 4 in. and $2 \times 4$ in. which proceeded untrimmed to the green chain. Thus, only one man was required 
on the mill floor. When visited, the unit was producing around $30,000 \mathrm{fbm}$ of lumber and 84 cunits of chips but it was obvious that both lumber production and recovery at the expense of chips could be greatly improved with more efficient operation. Power requirements for Beaver unit and dimension machine were estimated at $500 \mathrm{hp}$.

It is reported that the more recent Beaver installations can handle logs up to 24 inches in diameter with a production claimed in excess of $100,000 \mathrm{fbm}$ per eight-hour shift.

(b) CHIP-N-SAW manufactured by Canadian Car (Pacific), Division of Hawker Siddeley Canada Ltd., Vancouver, B.C. The Chip-N-Saw has an infeed mechanism consisting of top and bottom chains, of which the latter is driven, which also can be positioned to aid in log centering. The top chain is fitted with attachments with a concave profile for log alignment and weighted drums to load the log sufficiently to provide positive feed through the top and bottom chipping heads.

The basic unit of the Chip-N-Saw produces a Profiled cant (ordinary cants can also be produced on other models). This is achieved by a stationary bottom cutterhead consisting of five head sections in three diameters to form a concave chipping head with stepped profile. The bottom cutterhead cutting first allows the smooth edge thus created to slide along a short bed plate to act as a guide for the top cutterhead. This has the same construction as the bottom head but is mounted on housings on a slide frame which is positioned by a cylinder. The side cutterheads are cylindrical in form, and they are mounted in housings on pivoted frames.

The profiled cant (Figure 1) passes directly from the chipping section, positioned by knurled feed rolls through a double-arbor saw section, four or five saws to each arbor depending on the profile, producing 2 in. lumber from the central core and 1 in. lumber from the sides of the cant.

In the unit seen at Lelco, Inc., Bend, Oregon, run by one man on the mill floor, lineal feed speed obtained was around 60 feet a minute, with a daily average of $37,000 \mathrm{fbm}$ of logs being cut on an eighthour shift. Recent claims by the manufacturer indicate that much higher lineal feed speeds (90 f.p.m.) can now be obtained. Power requirement for the basic unit is estimated at $553 \mathrm{hp}$. An "edge chipper" has also recently been developed by this company. (c) H-P CHIPPER CANTER manufactured by Soderhamn Works, Talladega, Ala. (Figure 2). (Distributed in Canada by Forano Ltd., Plessisville, Quebec.) The 18 in. unit manufactured by this company consists of two convex discs, about $60 \mathrm{in}$. in diameter rotating on the same axis. Each disc has two spirals on it, 33 knives set to a spiral or 132 knives in all, each knife being about $1 \frac{1}{2}$ in. wide. The discs rotate in a counter-clockwise direction at up to 700 r.p.m. with log infeed speed of 160 feet a minute. The retraction of the discs to an opening equivalent to the width of the desired cant will permit squaring two sides of the log. The two-sided log can then either be conveyed back to the infeed again or, as in the system used at the Consolidated-Bathurst's Peribonka mill, pass to a second unit, where either a square or rectangular cant is obtained. The cant then passes to an edger for further processing.

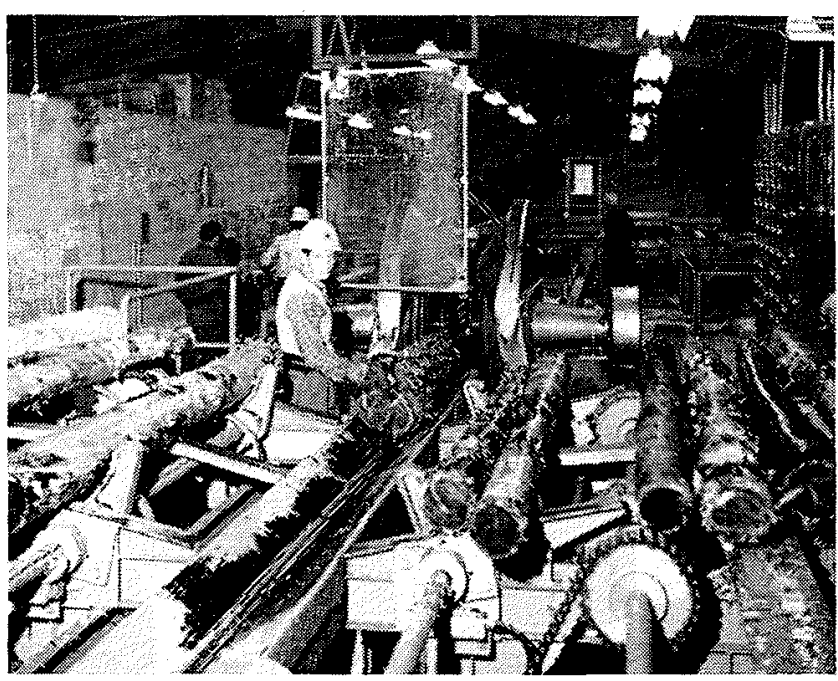

Figure 2. "H-P Chipper Canter at Consolidated-Bathurst's Peribonko Mill"

Different infeeds are required for the first and second units at the mill. For the first unit which takes the log, a V-shaped steel trough with a feed chain driven by a reversible electric drive is used. This incorporates a mechanical adjustment for speed to match the feed rate of the unit. The infeed to the second unit contains a power unit to line up the cant by means of spiral rolls and a driven roll section with press-down roller set immediately in front of the canter. Shadow lines assist the machine operator in determining optimum widths.

Production at this mill which is operating on two shifts is around $40,000 \mathrm{fbm}$ per shift with 1.6 oven dry tons of chips produced per $M$ feet of logs sawn. One operator is required for each unit and another at the edger as this is a completely independent installation. Power requirement for each unit is $150 \mathrm{hp}$.

(d) CHIP-O-MATIC manufactured by J. A. Vance Company, Winston-Salem, N.C. This chipper-canter was introduced by the Vance Company at the 1967 Southern Pine Exposition in New Orleans and was seen in operation there. There are now several commercial installations of this unit in the Southern U.S.A.

Profiled cant from a $10 "$ log 
The Chip-O-Matic has an infeed in which the log on entering the unit is held by two rolling centre guides and carried through the unit by eight spiked rollers (4 lower power rollers and 4 upper pressure rollers) at around 100 feet per minute. Chipping is accomplished by two opposed end-milling cutterhead discs. Each disc is fitted with four scoring and four chip-severing flat knives, positioned at a $45 \mathrm{de}$ gree angle, with discs rotating at $350 \mathrm{rpm}$, and each disc driven by a $100 \mathrm{hp}$ motor.

\section{References}

ANONYMOUS. 1966. Mechanization for utilization. Pulp Paper Mag. Can. 67 (C): WR 122-WR 126.

ANONYMOUS. 1967. The Vance Chip-O-Matic canter. Pulpwood Production 15 (4): 22, 24.

DOBIE, J. 1967. Chipper headrig productivity cuts small log milling costs. For. Industries 94 (9): 82 85. Slightly modified version, with bibliography,

\section{CORRECTION}

The captions for the photographs of Dr. G. W. I. Creighton and R. H. Burgess in the April, 1968 Chronicle were reversed.

The correct photographs are below:

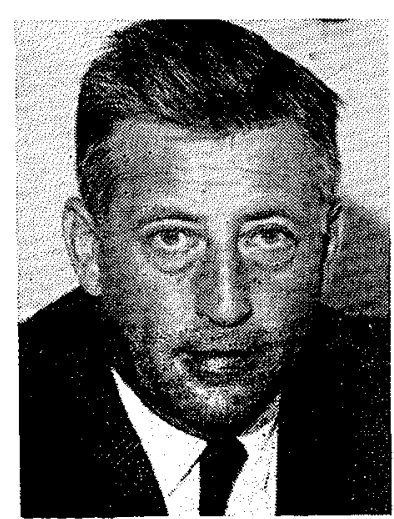

R. H. Burgess

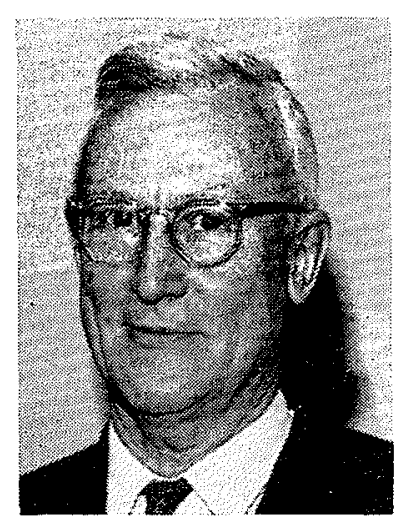

Dr. G. W. I. Creighton
Like the H-P chipper-canter, the Chip-O-Matic will require either two passes of the log through the same machine or two machines in series if a squared cant is to be produced. Additional processing either using an edger, a line bar band resaw or both would of course be independent of the primary processing unit. The company also has a chipperedger operating on the same principle as the main unit.

published 1967, as How chipper headrigs reduce small-log processing costs. Can. For. Industries 87 (8): 60-65.

DUFRESNE, R. 1967. H-P canter-chipper is hub of Quebec small-log sawmill. Can. For. Industries 87 (1): 53-56.

HEATH, V. 1967. With chipper headrig, small-log processing can be profitable. Can. For. Industries 87 (8): 68-71, 73.

\section{CORRECTION}

In the paper by W. Stanek entitled "Development of black spruce layers in Quebec and Ontario" in the April 1968 Chronicle, the Figure 1 on page 26 was incorrect. The correct Figure 1 should have been as follows:

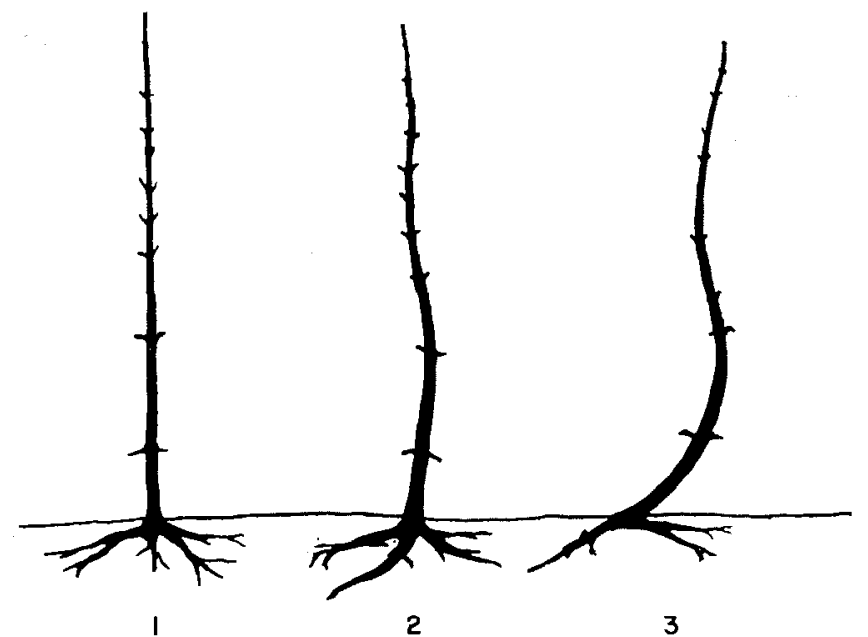

Figure 1. The arbitrarily defined stem-form classes for black spruce: good (1); medium (2); poor (3). 